\title{
Assessment of bioavailability of some potential toxic metals in mining-affected soils using EDTA extraction and principle component analysis (PCA) approach, Derbyshire, UK
}

\author{
Zahid O. Alibrahim ${ }^{1,2 *}$ and Craig D. Williams ${ }^{2}$ \\ ${ }^{1}$ Faculty of Science and Engineering, Koya University, Erbil, Iraq \\ ${ }^{2}$ School of Applied Science, Wolverhampton University, Wulfruna Street, WV1 1LY, UK
}

\begin{abstract}
The current study area has long mining history for copper, lead, and zinc. As a result, these metals may have elevated levels and pose a potential risk to the surrounding area. This area is currently being used for agriculture and sheep rearing, therefore, the bioavailable fraction of some selected heavy metals namely $(\mathrm{Cu}, \mathrm{Pb}, \mathrm{Zn}, \mathrm{Mn}$, $\mathrm{Cr}, \mathrm{Ni}$, and $\mathrm{V}$ ) has been evaluated using $0.01 \mathrm{M}$ EDTA procedure, as this would help for better understanding of the risk that these heavy metals can pose to living organisms. A total of 51 samples of topsoils, floodplain soils, and stream sediment soils were collected and analysed for their total concentrations using ICP (Inductively Coupled Plasma) optical emission spectroscopy. Results show that, depending on the bioavailable ratio, soil samples have the biggest EDTA extractable amount for all studied metals, except for $\mathrm{Mn}$ and $\mathrm{Cr}$ for which highest levels were found in the floodplain samples. However, based on national bioavailable mean amount in England and Wales, the amount of EDTA metal extractable for all selected metals from soil samples are exceeded the national average amounts of England and Wales, except for $\mathrm{Mn}$ and $\mathrm{Ni}$, whereas in floodplain and stream sediment samples, all EDTA metals extractions are lower than the national mean levels, except $\mathrm{Cu}$ and $\mathrm{Zn}$ for flood plan samples. Principal component analysis (PCA) technique was performed to investigate how the bioavailable fractions of studied metals and factors namely (organic matter contents, soil $\mathrm{pH}$, and different granulometric ranges) are correlated. Results show that both organic matter amounts and fine fractions (clay and silt) were the master factors controlling the bioavailable portion in all soil types.
\end{abstract}

\section{Introduction}

Nowadays a big consideration was given to the pollution of potentially toxic metals and their adverse effects to the ecological system and human health. As a result, lots of studies have been performed to investigate and measuring these constituents as they have the ability to accumulate in the upper layer of soil profile posing environmental risk to the surrounding area (Weber and Karczewska, 2004). Therefore, indicating and measuring the bioavailable amount is very important because it will help for better understanding and estimating of the risk that heavy metals can pose to living organisms. To this end, different researchers have used different chemical reagent to extract the bioavailable fraction because a particular reagent which could be suitable to extract a specific pollutant in some area might not be appropriate for the same metals in different location [1]. To predict and simulate the bioavailable fraction of heavy metals in soil and sediment, researchers have used a wide range of extractants including, mineral acids such as $1 \mathrm{~N} \mathrm{HCl}$, buffer solutions for example $1 \mathrm{M} \mathrm{NH}_{4} \mathrm{OAc}$, salt solutions for instance $0.1 \mathrm{M} \mathrm{CaCl}_{2}$, and chelation agents such as EDTA, which has been used in this study, and DTPA [2]. According to MAFF [3] and Gleyzes et al. [4], using Ethylene Diamine Tetra Acetic Acid (EDTA), which is considered to be bioavailable to plants, in one step extraction would help to extract the exchangeable, soluble and some of metals bound to carbonate and organic matter. In addition, EDTA, according to McGrath and Loveland [5] has also been used in England and Wales to extract the bioavailable fraction of some studied heavy metals in soils.
It would be worth noting that during the daily life of plants, it usually absorbs by its roots from the soil solution all required materials without considering if the absorbed metals are harmful or not, and thus will change the soil contents of different metals [6], For example, pointed out that metals in soil solution are in equilibrium state with the exchangeable phase which has linked to the surface of grain particles and the fraction absorbed by functional group of organic matter. As a result, plants will contribute to change the physical criteria of the soil surrounding them, and thereby influencing the bioavailability of heavy metals in soils [7]. Consequently, due to disturbance of the equilibrium state, some metals are very likely to be released to soil from other fractions to be available for plants which were not present before [8]. In addition, the natural processes such as weathering could change the form of metals in the soil and thus affect their mobility and bioavailability in soils. Moreover, there are many factors, such as $\mathrm{pH}$, $\mathrm{Eh}$, organic matter and clay mineral contents, and grain size, that play a significant role in changing the chemical form of heavy metal in soil, and thereby changing their bioavailability capacity in soil [6]. Inka [9],

Correspondence to: Zahid O. Alibrahim, Faculty of Science and Engineering, Koya University, Erbil, Iraq, E-mail: zahiid1000@yahoo.com

Key words: heavy metals, bioavailability, PCA, EDTA, national average, topsoils

Received: November 29, 2016; Accepted: December 23, 2016; Published: December 29, 2016 
for instance, have found that $\mathrm{pH}$ of the soil is the key soil variable that controls speciation and bioavailability of vanadium species in studied samples.

In the current study, bioavailability of some selected heavy metals to plants will be evaluated and considered because the majority of the study area at the present time is mainly used for stock rearing and agriculture purposes (Figure1). As a result, heavy metals are very likely to be transferred to human beings via plants and animal products. According to Mench and Martin [10], potentially toxic metals, such as $\mathrm{Cu}, \mathrm{Pb}, \mathrm{Ni}, \mathrm{Cd}, \mathrm{Co}, \mathrm{Hg}$, after been taken by plants, they could be moved directly to human body when eating plants and animals grazing on it. In addition, in areas with long mining history such as the current study area, high amount of heavy metals (e.g. $\mathrm{Cd}, \mathrm{Pb}$ ) could be transferred to animal body via ingestion of fine soil containing harmful metals when grazing grass, this will be a significant pathway of soil-grass-animal by which metals are entering grazing animals, and thereby human body [11]. Therefore, measuring the bioavailable fraction of heavy metals is very crucial when appraising pollution and potential risk assessment [2]. Accordingly, the key objectives of the current work are to examine the total concentration of heavy metals so that their bioavailable ratio can be evaluated. This would be followed by the assessment of the calculated bioavailable ratios by comparing with those of England and Wales. Finally, specify the relationship of $\mathrm{pH}$, organic matter, and grain size of the soil with the bioavailable fraction of examined heavy metals using principal component analysis technique (PCA).

\section{Materials and methods}

\section{The study area}

The study area, Ecton mining area, is located in the southern part of the Peak District in Derbyshire, England. It is bounded by the River Manifold from the west (Figure 1). This area has been mined for a long period, from the times of the Roman Empire the focus was on the production of $\mathrm{Pb}$, and from the period of the 16th century till the mid of the 19th century, the production of $\mathrm{Zn}$ was very important. $\mathrm{Zn}, \mathrm{Pb}$, and more recently fluorspar (calcium fluoride), on the Carboniferous Limestone, have been extracted extensively for a long time, from linear outcrops at the surface which are called locally "rakes" [12]. As a result, huge amounts of heavy metals were released to the surrounding area and are most likely to be a significant source of heavy metals contamination to the local soil, water, and vegetation. In addition, as the area is principally used for pastures to cattle and sheep, it is likely that contaminant metals could access the human body via the soilanimal-human pathway, thereby posing a potential risk to human health.

\section{Geological setting of the study area}

The geology of the area has been described by Harris [13], who pointed out that during the period of Devonian to Tertiary, the majority of England and Wales was covered by the following sedimentation units:

1. During the period (Permian- Triassic) the lithology was Sandstone and the majority is red sandstone, during the Cretaceous was a Greensand and Bagshot bed in Tertiary.

2. In Carboniferous and Jurassic, the common lithology was shales

3. Finally, the Limestone lithology was predominant in Carboniferous and Jurassic.

However, According to Cope [14], the study area is characterised by its bedrocks that consist of Carboniferous Limestone (Dinantian) (Figure 2), which affects both topography and hydrogeology of the area and From borehole data, the minimum thickness of Dinantian rocks is about $(600 \mathrm{~m})$ around Buxton, and about (1000 $\mathrm{m})$ at Eyam area [15].

\section{Sample collection and preparation}

Fifty-one topsoil, floodplain, and stream sediment samples $(37,11$, and 3 samples respectively) have been collected from the study area (Figure 3).

The geographical coordinates (Northing and Easting) for all collected samples were recorded at the time of samples collection using a Global Positioning System (GPS) tool, as these will be used to plot samples locations when using GIS software for sample locations map. With regards to flood plain soils, a section across flood plain, near Ecton Bridge, was taken. From the channel of the Manifold River a

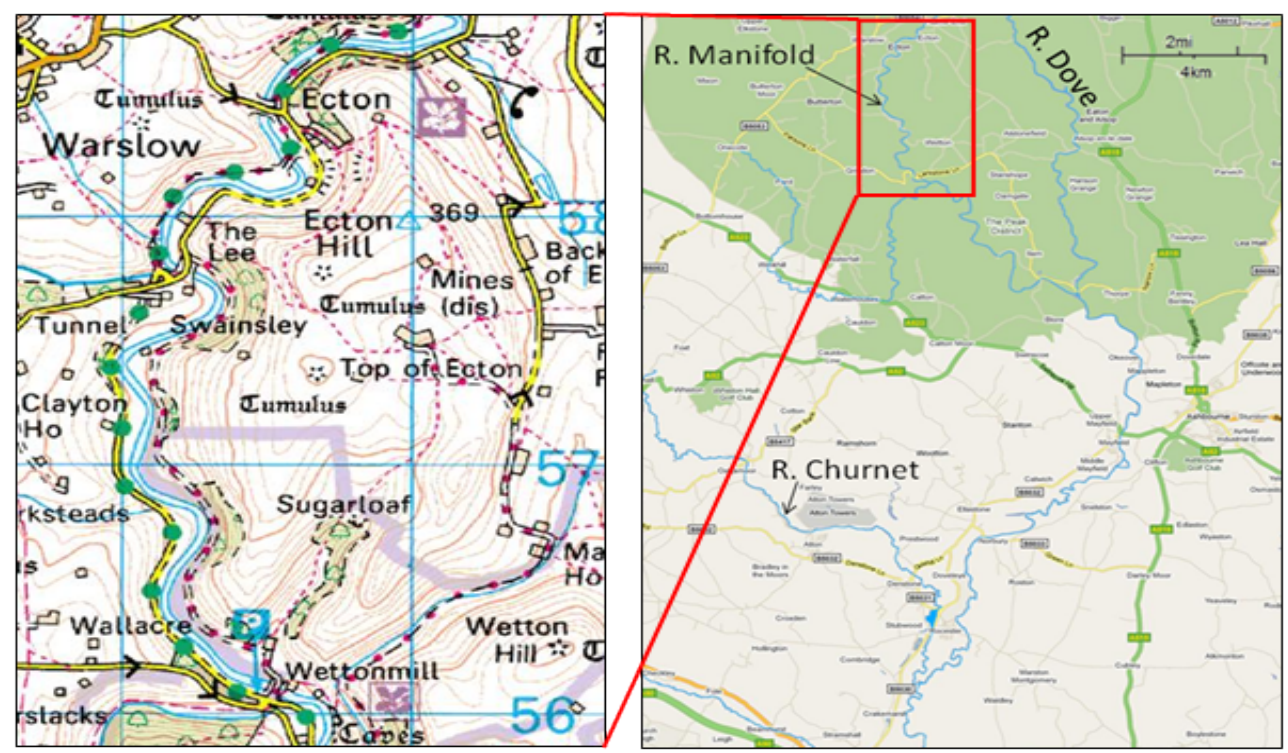

Figure 1. Map showing the location of study area (Ecton mining area). Source (modified from Ordinance Survey et al., 2009). 


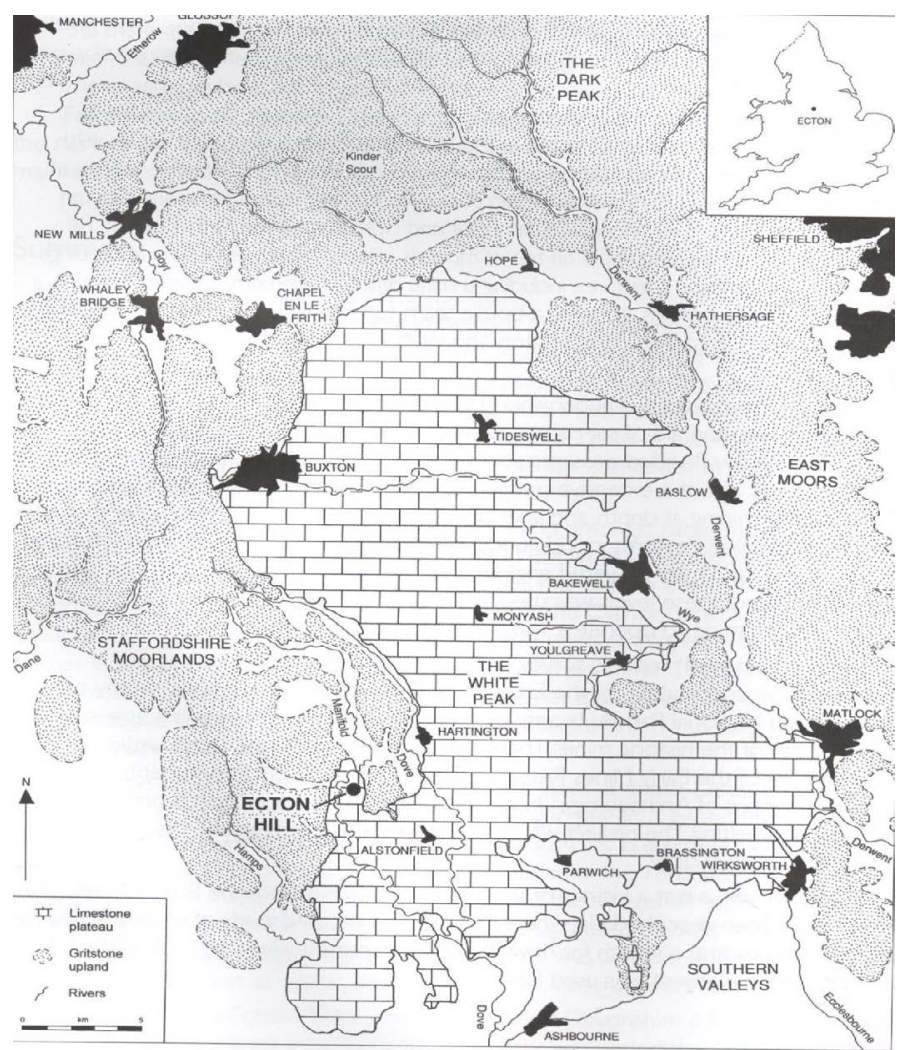

Figure 2. Map of Peak District, Showing the study area (Ecton Hill) which covered by Carboniferous Limestone (adopted from Barnatt, 2013).

total of 11 samples were collected with an interval of 5 metres. The following procedure was adopted to prepare samples for analysis as has been mentioned by some researchers, for instance $[16,17]$.

1. Once the sample bags have been brought to the lab, all contents were distributed out on a stainless-steel tray, followed by disaggregation of large pieces and pieces of wood and plant roots were removed, and all containers were labelled clearly.

2. In the lab all trays were placed in an open space on the allocated bench at normal temperature for about seven days with turning over and mixing the samples one time every day, until all samples were completely dried.

3. When the samples had quite dried, they were sieved using a $2 \mathrm{~mm}$ sieve.

4. Again large pieces of sample which were left on the sieve were broken down by porcelain pestle and mortar and passed through the sieve. After that, all samples were kept in polyethylene sealable bags with suitable labelling (i.e., sample name and sieved grain size) in cupboard until the necessary analyses had been done.

\section{Chemical analysis}

Total concentrations of heavy metals were determined using the ICP-OES facility at the University of Wolverhampton, UK. Although, the best way for determining the total concentration of heavy metals is by digesting samples with strong concentrated acids for instance hydrofluoric acid (HF), nitric acids $\mathrm{HNO}_{3}$ /perchloric acid $\mathrm{HClO} 4$ $[18,19]$, but these acids were ruled out due to safety reasons while working in the lab. Consequently, instead, samples were digested using a mixture of nitric acid and hydrogen peroxide $\mathrm{H} 2 \mathrm{O} 2$. $0.5 \mathrm{gm}$ of fine

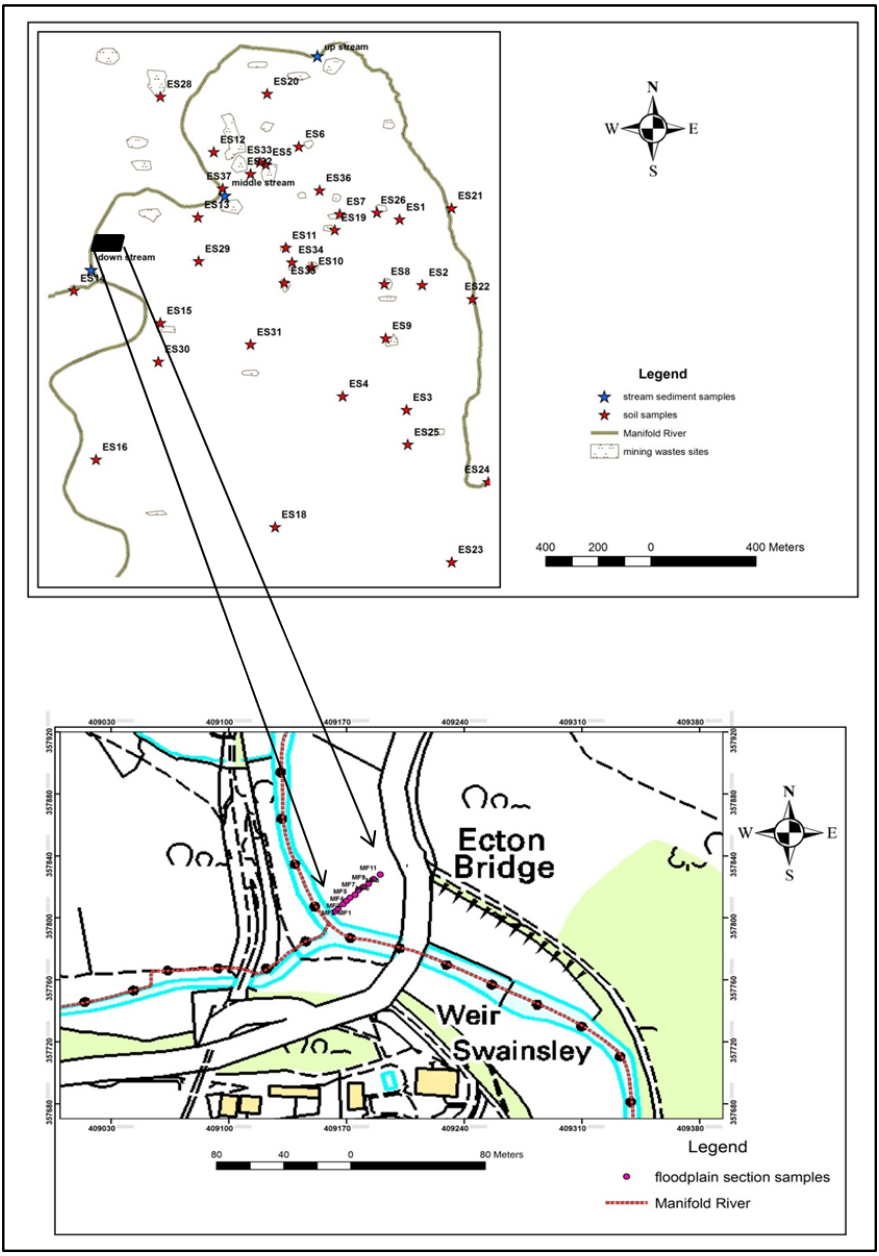

Figure 3. Map of the study area showing locations of collected samples.

grind of each sample was digested with $5 \mathrm{ml}$ of nitric acid and $1 \mathrm{ml}$ of hydrogen peroxide in a Milestone Ethos 900 Microwave digester using a program of four stages. The program was set to run at different setting (250W, 400W, and 650W) for about one hour.

The bioavailable fraction of heavy metals in soil and sediments for the current study was determined. Many researchers have used different ways to simulate the bioavailable fraction of elements in soils, because there is no a specific international way to achieve this task. However, some researcher such as Quevauviller [20] who has compared different ways in order to find the best method which gives a good simulation for the bioavailable fraction of heavy metals in soils and sediments. This researcher pointed out that EDTA (Ethylene Diamine Tetra Acetic Acid) method for estimating the bioavailable fraction is a good procedure. In addition, Ministry of Agriculture, Fisheries, and Food [3] highlighted that the best method for determining the bioavailable fraction of $\mathrm{Cu}, \mathrm{Pb}, \mathrm{Zn}, \mathrm{Cd}$, and $\mathrm{Ni}$ is using (0.05 M EDTA) ammonium salt at a $\mathrm{pH}$ of 7 and temperature of $20^{\circ} \mathrm{C}$. Furthermore, McGrath and Loveland [5] have pointed out that as a part of the national geochemical survey in England and Wales for the determination of the bioavailable fraction of $\mathrm{Cd}, \mathrm{Co}, \mathrm{Cu}, \mathrm{Pb}, \mathrm{Mn}, \mathrm{Zn}$, and $\mathrm{Ni}$, EDTA extraction method was used to achieve the mentioned task. As a result, EDTA extraction method was commonly been used in various studies, and in the current study the method of MAFF will be adopted to find the bioavailable fraction, which its procedure has the following steps: 
1- $\quad$ A sample portion of $5 \mathrm{gm}( \pm 0.01)$ was taken into a class bottle of $250 \mathrm{ml}$ capacity

2- After 0.05M of EDTA ammonium salt was prepared, $100 \mathrm{ml}$ of the solution was added to the sample.

3- The bottle (sample and EDTA) was placed on the shaker, and been shaken for one hour.

4- After the shaking process, the mixture of the bottle was filtered using No. 1 filter paper.

5- The EDTA extract solution was kept in small plastic bottles and transferred for analysing using ICP-OES and result where been expressed in unit of $\mathrm{mg} / \mathrm{kg}$ of the dried sample. All samples in the current study were analysed using the ICP-OES instrument.

\section{Statistical analysis}

Using SPSS software package (Windows version 20) descriptive statistical parameters (Max, Min, Average, and SD.) have been calculated to be used later for the determination of the bioavailable ratio of the studied heavy metals. In addition, the possible correlation between the bioavailable ratio and total heavy metals concentration was specified using person correlation matrix. Multivariate analysis of the data was achieved using principal component analysis (PCA) technique to indicate the relation between the bioavailable fraction of examined metals and key soil parameters $(\mathrm{pH}$, organic matter, and various granulometric sizes). The locations of collected samples have been plotted using Arc-GIS 10.1 software package. Finally, it is worth noting that the accuracy of sample analysis was controlled using blank and duplicate samples during running of ICP-OES facility.

\section{Results and discussion}

\section{Bioavailable fractions}

The bioavailable fractions of studied heavy metals have been determined using EDTA extraction method (refer to chemical analysis section). Summary statistics of findings are shown in Table 1.

From table 1, it could be seen that the bioavailable fraction for all metals are various between different sample types. For instance, the EDTA average amount for $\mathrm{Cu}$ is ranged from $3.58 \mathrm{mg} / \mathrm{kg}$ to 22.58 $\mathrm{mg} / \mathrm{kg}$ for stream sediment and soil samples, respectively. The EDTA extractable for all metals was the lowest in the stream sediment samples. However, soil samples have the biggest EDTA extractable amount for all metals except for $\mathrm{Mn}, \mathrm{Cr}$, and $\mathrm{Ni}$ with the highest levels in the floodplain samples (Table 1). $\mathrm{Cu}, \mathrm{Pb}$, and $\mathrm{Zn}$ are the main metals which were extracted during mining operations in the area (refer to chap.2, mining history section). As a result, these metals are more likely to have the highest levels of EDTA extractions in soil samples with bioavailable amount decrease in the order soil samples > floodplain samples $>$ stream sediment samples. It could be seen that $\mathrm{Cu}, \mathrm{Pb}$, and $\mathrm{Zn}$ have high levels of bioavailable fraction. This is more likely due to the fact that the former anthropogenic activities in the area are the possible source for such elevated concentrations. As has been mentioned earlier, because Ecton mining area has long mining history and for long period to extract these metals from sulphide ores (refer to mining history in chap. 2). Therefore, high levels of EDTA extractable metals are most likely affected by the high concentrations of these metals in the soil of the area and the procedure of extraction as well [2].

\section{Bioavailable ratio}

In the current study this method has been used to examine the bioavailable fraction of studied metals to plant for the collected samples. This approach represents the ratio of bioavailable fraction of individual heavy metal to its total amount in the sample, and can be calculated using the following equation $[21,22]$ :

Bioavailable Ratio $(\%)=($ Bioavailable metal fraction/Total metal concentration in soil) $\times 100$

This approach depends on the calculated bioavailable fraction of heavy metal to plants in soil, which has been measured using chemical reagents (EDTA) as it has been mentioned before (refer to chemical analysis section). Results of the bioavailable ratios of the studied elements are shown in Table 2.

On the basis of the calculated bioavailable ratios, results show that the bioavailable ratio of the studied heavy metals has the following order: $\mathrm{Pb}>\mathrm{Mn}>\mathrm{Zn}>\mathrm{Cu}>\mathrm{Ni}>\mathrm{V}>\mathrm{Cr}$ for soil samples, $\mathrm{Mn}>\mathrm{Cu}>\mathrm{Pb}>$ $\mathrm{Zn}>\mathrm{Ni}>\mathrm{Cr}>\mathrm{V}$ for floodplain samples, and $\mathrm{Mn}>\mathrm{Pb}>\mathrm{Cu}>\mathrm{Zn}>\mathrm{Ni}>\mathrm{Cr}>$ $\mathrm{V}$ for stream sediment samples. It is obvious that in all sample types, $\mathrm{Cu}, \mathrm{Pb}, \mathrm{Zn}$, and $\mathrm{Mn}$ have the highest bioavailable ratios. However, $\mathrm{Cr}$, $\mathrm{Ni}$, and $\mathrm{V}$ have the lowest values of the bioavailable ratios. Generally, within all sample types, $\mathrm{Cu}, \mathrm{Pb}$, and $\mathrm{Zn}$ illustrate high levels of

Table 1. Descriptive statistics for average amount of EDTA extractable metal fractions in collected samples at the study area ( $\mathrm{mg} / \mathrm{kg})$.

\begin{tabular}{|c|c|c|c|c|c|c|c|}
\hline All sample types & $\mathrm{Cu}$ & $\mathbf{P b}$ & Zn & Mn & $\mathrm{Cr}$ & $\mathbf{N i}$ & $\mathbf{V}$ \\
\hline \multicolumn{8}{|l|}{ Soil samples $(\mathrm{n}=37)$} \\
\hline $\operatorname{Max}$ & 188.86 & 2244.40 & 634.07 & 238.88 & 0.22 & 2.15 & 0.94 \\
\hline Min & 0.81 & 1.58 & 0.82 & 4.29 & 0.02 & 0.14 & 0.03 \\
\hline Average & 22.65 & 207.58 & 104.01 & 67.65 & 0.08 & 0.82 & 0.18 \\
\hline SD & 42.36 & 453.42 & 169.04 & 59.71 & 0.05 & 0.56 & 0.19 \\
\hline \multicolumn{8}{|c|}{ Floodplain samples $(\mathrm{n}=11)$} \\
\hline Max & 23.45 & 31.80 & 80.79 & 117.55 & 0.13 & 1.11 & 0.22 \\
\hline Min & 2.37 & 4.30 & 6.22 & 35.90 & 0.05 & 0.66 & 0.01 \\
\hline Average & 9.07 & 14.32 & 20.24 & 79.82 & 0.09 & 0.86 & 0.06 \\
\hline SD & 5.27 & 6.88 & 21.66 & 23.74 & 0.02 & 0.16 & 0.06 \\
\hline \multicolumn{8}{|c|}{ Stream sediments samples $(n=3)$} \\
\hline Max & 7.63 & 11.53 & 11.61 & 36.81 & 0.05 & 0.58 & 0.02 \\
\hline Min & 0.97 & 0.78 & 2.91 & 25.43 & 0.04 & 0.41 & 0.01 \\
\hline Average & 3.58 & 5.55 & 6.26 & 30.22 & 0.04 & 0.49 & 0.02 \\
\hline SD & 3.56 & 5.48 & 4.68 & 5.90 & 0.01 & 0.09 & 0.01 \\
\hline
\end{tabular}


Alibrahim ZO (2016) Assessment of bioavailability of some potential toxic metals in mining-affected soils using EDTA extraction and principle component analysis (PCA) approach, Derbyshire, UK

Table 2. Bioavailable ratio of the studied heavy metals at the study area $(\mathrm{mg} / \mathrm{kg})$.

\begin{tabular}{|c|c|c|c|c|c|c|c|}
\hline All sample types & $\mathrm{Cu}$ & $\mathbf{P b}$ & Zn & Mn & $\mathbf{C r}$ & $\mathbf{N i}$ & $\mathbf{V}$ \\
\hline \multicolumn{8}{|l|}{ Soil samples $(\mathrm{n}=37)$} \\
\hline Bioavailable Ratio (\%) & 3.81 & 6.53 & 4.49 & 6.30 & 0.22 & 2.15 & 0.47 \\
\hline \multicolumn{8}{|l|}{ Floodplain samples $(\mathrm{n}=11)$} \\
\hline Bioavailable Ratio (\%) & 6.77 & 6.36 & 5.09 & 7.57 & 0.19 & 2.35 & 0.18 \\
\hline \multicolumn{8}{|c|}{ Stream sediment samples $(\mathrm{n}=3)$} \\
\hline Bioavailable Ratio (\%) & 6.17 & 7.33 & 3.57 & 7.52 & 0.10 & 1.67 & 0.07 \\
\hline
\end{tabular}

Table 3. Showing times of EDTA metal extracted in all collected samples to national average amounts of England and Wales (adopted from McGrath and Loveland, 1992).

\begin{tabular}{|c|c|c|c|c|c|c|c|}
\hline All sample types & $\mathbf{C u}$ & $\mathbf{P b}$ & Zn & Mn & $\mathrm{Cr}$ & $\mathbf{N i}$ & $\mathbf{V}$ \\
\hline Soil samples $(n=37)$ & 3.53 & 7.47 & 10.72 & 0.42 & n.a & 0.52 & n.a \\
\hline Floodplain samples $(\mathrm{n}=11)$ & 1.30 & 0.49 & 1.65 & 0.50 & n.a & 0.53 & n.a \\
\hline Stream sediments samples $(n=3)$ & 0.56 & 0.20 & 0.65 & 0.19 & n.a & 0.30 & n.a \\
\hline National average values & 6.4 & 27.8 & 9.7 & $159 . .5$ & n.a & 1.6 & n.a \\
\hline
\end{tabular}

bioavailable ratios, suggesting the anthropogenic source of these metals due to the fact that these metals have been extracted extensively and for long time in this area. It should be noted that, however, the majority of studied metals have approximately similar bioavailable ratios (Table 2) between different soil types in spite of their EDTA fractions and total concentrations are quite different among various soil types. For instance, the total concentration of $\mathrm{Pb}$ is $3176.95 \mathrm{mg} / \mathrm{kg}$ in soil samples and $225.32 \mathrm{mg} / \mathrm{kg}$ in floodplain soils, whereas, its bioavailable ratios are $6.53 \%$ and $6.36 \%$ respectively, which are quite close to each other. $\mathrm{Cu}$ has a total concentration of $134 \mathrm{mg} / \mathrm{kg}$ and $58 \mathrm{mg} / \mathrm{kg}$ in floodplain and stream sediment samples, but it has bioavailable ratios of $6.77 \%$ and $6.17 \%$ respectively. Another example is the case of $\mathrm{Zn}$, which has a total concentration of $2314.68 \mathrm{mg} / \mathrm{kg}$ and $397.36 \mathrm{mg} / \mathrm{kg}$ in soil samples and floodplain soils respectively, but its bioavailable ratios in these two soil types are $4.49 \%$ and $5.09 \%$ respectively.

The bioavailable ratio of $\mathrm{Cu}, \mathrm{Pb}$, and $\mathrm{Zn}$ has also been estimated by Bradley and Cox [22] using $\mathrm{MgCl}_{2}$ extraction. These authors have recorded bioavailable ratios of $7.3 \%, 1.5 \%$, and $30 \%$ for $\mathrm{Pb}, \mathrm{Zn}$, and $\mathrm{Cu}$, respectively in floodplain soils of the Rivers Hamps and Manifold. The previous authors have found that the bioavailable ratio was in the following order: $\mathrm{Zn}>\mathrm{Pb}>\mathrm{Cu}$, which is different from that of this study (i.e., $\mathrm{Cu}>\mathrm{Pb}>\mathrm{Zn}$ ). The difference in bioavailability order of these metals between current study and that of Bradley and Cox [23] is very likely due to the use a different chemical reagent, because these authors have used $\mathrm{MgCl}_{2}$ for extraction which is different from that of this study (EDTA). However, in both studies $\mathrm{Pb}$ shows the same bioavailable order in spite of the difference in bioavailability. In the current study $\mathrm{Pb}$ has the first order of bioavailability in soil samples, and the second order in stream sediment samples. Likewise, Bradley and Cox [23] reported that $\mathrm{Pb}$ was the most predominant in both exchangeable and $\mathrm{Fe} / \mathrm{Mn}$ oxide forms. However, in the case of $\mathrm{Cu}$, in the current study, this element has the fourth, the second and the third bioavailable order in soil samples, floodplain, and stream sediment samples, respectively. In the same way, this element has been reported by Bradley and Cox [23], to be very important fraction in both $\mathrm{Fe} / \mathrm{Mn}$ oxide and residue fractions. However, the bioavailable ratio of $\mathrm{Zn}, \mathrm{Cr}, \mathrm{Ni}$, and $\mathrm{V}$ was the lowest and this may indicate that these metals were mostly available in the residual phase from which EDTA can just extract a small amount of these metals. Another example is the study conducted by Abrahams and Steigmajer [24], who examined the bioavailability of $\mathrm{Cu}, \mathrm{Pb}$, and $\mathrm{Zn}$ from soils in Mid-Wales using EDTA extraction. These authors have observed that the bioavailable ratios of the studied metals have the following order: $\mathrm{Pb}>\mathrm{Cu}>\mathrm{Zn}$, with the highest bioavailable ratios of
46.9\% for $\mathrm{Pb}$. This order of bioavailability is similar to that of the current research of the collected stream sediment samples. In addition, the bioavailability of these metals is also been examined by Lacatusu [25] in Romania from soils influenced by non-ferrous industrial activities. According to this study, the bioavailable ratio of studied metals has the order: $\mathrm{Pb}>\mathrm{Cu}>\mathrm{Zn}$, which is quite similar to that order of the present study for the collected stream sediment samples. It could be concluded that metals exhibit various bioavailability ratios in different soil types, and the bioavailability fractions depend on many factors, including metal species, plan types, and soil parameters such as cation exchange capacity, $\mathrm{pH}$, and redox potential $[26,27]$.

\section{Assessment of EDTA extractable metal fractions at the study area on the basis of the national mean amounts}

As has been mentioned earlier 0all collected samples from the study area have been analysed for their bioavailable fractions of investigated metals $(\mathrm{Cu}, \mathrm{Pb}, \mathrm{Zn}, \mathrm{Mn}, \mathrm{Cr}, \mathrm{Ni}$, and $\mathrm{V})$ using a $0.05 \mathrm{M}$ EDTA solution at $\mathrm{pH} 7$, summary statistics are available in Table 1 , Therefore it is very important to know and appraise how high the extracted levels are by comparing the calculated amounts with the national average levels which have been listed in table 3 . These levels have been adopted from McGrath and Loveland [5] who pointed out that the EDTA extraction amounts of metals mentioned in table 5 in England and Wales have been measured and displayed in $\mathrm{mg}$ per $1 \mathrm{~kg}$ of dried soil of samples. The bioavailable fractions (i.e., ETDA metal extraction) of selected metals in all collected samples have been compared with the national mean values of England and Wales [5] (Table 3). Results are shown in Table 3.

From this table, the focus will be on $\mathrm{Cu}, \mathrm{Pb}$, and $\mathrm{Zn}$ because these metals have been mainly extracted from the study area and for a long time (refer to mining history, chap 2). It could be seen that the amount of EDTA metal extractable for all selected metals from soil samples are exceeded the national average amounts of England and Wales, except for $\mathrm{Mn}$ and $\mathrm{Ni}$. The EDTA $\mathrm{Cu}, \mathrm{Pb}$, and $\mathrm{Zn}$ in soil samples are 3.53, 7.47, and 10.72 , respectively, times the national average amounts. However, with regards to floodplain and stream sediment samples, all EDTA metals extractions are lower than the national mean levels, except $\mathrm{Cu}$ and $\mathrm{Zn}$ for flood plan samples. When the area had been explored during the time of sampling, the majority of the area was found to be used mainly for cattle rearing and crop production. As a result, high EDTA metal extraction in soils over the area can highlight a large risk to animals and human beings through the soil- plants-animals- human body exposure pathway. In addition, according to Archer and Hodgson 
[28] and ICRCL [11], Cu, Zn, and Ni have a toxic threshold of EDTA value of $70 \mathrm{mg} / \mathrm{l}, 130 \mathrm{mg} / \mathrm{l}$, and $20 \mathrm{mg} / \mathrm{l}$, respectively. Above these limits, the bioavailable fractions of these metals will have toxic effects on the grazing animals, and thereby influence the human adversely. Over all, based on the above guideline for $\mathrm{Cu}, \mathrm{Zn}$, and $\mathrm{Ni}$ and calculated EDTA trace element extractions for each sample (see appendix $\mathrm{x}$ for EDTA metal amount for individual samples) all locations where samples were collected from are safe with respect to toxicity, except in samples ES6, ES7, ES8, ES9, ES26, ES32, and ES37 for Zn, and ES9, ES9, ES32, and ES37 for $\mathrm{Cu}$. The possible source for such levels is more likely to be anthropogenic than natural enrichment because the area was mined for sulphide ore minerals for a long time (refer to mining history in chap.).

\section{Relationship between EDTA metal extractions (i.e., Bioavailable fraction) and the total amount of metal concentration}

Although, the total concentration of heavy metals in soils is very significant as it gives information regarding the degree of contamination in soil of interest [29], it does not give information about heavy metals speciation and their bioavailability, and hence supply only a little knowledge about the effects of potentially toxic metals on the living organisms [18]. Therefore, measuring the bioavailability of heavy metals is more important when studying their high-level consequences on the surrounding environment. To this end, all collected samples (i.e., soil, floodplain, and stream sediment samples) were extracted for their bioavailable amount of heavy metals using a 0.05 M EDTA solution, pH 7 (refer to chap. 3). The relationship of this fraction with the total concentration was investigated because such correlation may provide useful information if there is any link between both levels. The relationship between the EDTA metals in studied samples and the total is shown in table 8 .

From Table 8, based on the correlation coefficient ( $r$ ) and level of significant, it could be seen that a strong positive correlation was found between EDTA metal fraction and their total concentration for $\mathrm{Cu}, \mathrm{Pb}$, $\mathrm{Zn}, \mathrm{Mn}$ for all sample types, except for $\mathrm{Pb}$ and $\mathrm{Mn}$ in floodplain samples and stream sediment samples respectively. Similarly, according to McGrath and Loveland [5], such strong correlations between EDTA $\mathrm{Cu}, \mathrm{Pb}, \mathrm{Zn}, \mathrm{Mn}$ and their total concentrations were found in England and Wales with EDTA Ni fraction linked weakly with their total concentration. In addition, a strong positive correlation for $\mathrm{Cu}, \mathrm{Pb}, \mathrm{Zn}$, and $\mathrm{Mn}$ is also reported by Hernandez and Pastor [30] in Sierra de Guadarrama in Spain for areas covering a former mine. However, a strong negative correlation was found for EDTA Cr fraction and its total concentration (Table 4). This is more likely due to the low solubility of Cr in soil [7] leading it to being less available for plants, and thereby having a negative correlation with the total amount. Regarding the correlation between the EDTA V Fraction and the total amount (Table 4 ), it is clear that this element has displayed a weak correlation between the bioavailable and the total amount. The possible explanation of such relation may be from the fact that this element, as pointed out by Cheshire et al., [31], has strong association with humic and fulvic acid in soil which makes it less extractable and available to plant, and hence weak relation between the available and total concentration. Overall, focusing on the metals, i.e., $\mathrm{Cu}, \mathrm{Pb}$, and $\mathrm{Zn}$, which have been extensively mined from study area (refer to mineralization section in chap. 2), it would be worth to note that a positive correlation between these EDTA metal fractions and the total amount may suggest that the EDTA fractions will rise with growing the total amount. For example, Yaru and Buckney [32] were found that all the metal extractions from sequential extraction in soils from Papua New Guinea were correlated strongly with the total $\mathrm{Cu}$ amount.

\section{Principal component analysis}

The key point of principle component analysis (PCA) is to eliminate the dimensional space of original datasets to new subsets of the variable of interest [33]. In this method of analysis, raw data have to be converted to principal components via eigenvalues by which the variance of extracted components are decreased on the basis of significance. To this end, in the current study the principal component analysis (PCA) approach was applied to find the possible associations between the bioavailable fractions of studied heavy metals and the physico-chemical properties of the soils (i.e., organic matter contents, $\mathrm{pH}$ value, and different granulometric data). Principal component analysis results for all soil types (i.e., topsoils, floodplain soils, and stream sediment samples), are shown in the Table 4,5 , and 6 , respectively. Eigenvalues and total variance explained for all collected samples are listed in the Table 4, 5, and 6.

In the case of soil samples, 4 principle components have been extracted which represent $70 \%$ of the total variance (Table 4). Results show that the first factor (F1) is mainly associated with the silt and clay fractions, with a positive relation with soil $\mathrm{pH}$, bioavailable fractions of $\mathrm{Zn}, \mathrm{Ni}$, and $\mathrm{V}$. This may indicate that fine particles (i.e., clay and silt), and $\mathrm{pH}$ are controlling the bioavailable fractions of these metals. According to Brady [34], the soil $\mathrm{pH}$ values in humid areas are ranged between $5-7$, which is similar to that of the current study in which the $\mathrm{pH}$ values for the majority of collected samples are below 7. As a result, such condition would provide more hydrogen ions $\left(\mathrm{H}^{+}\right)$to be available for competing metal cations for the binding sites on the clay and organic matter, resulting release metal ions, and thus high concentration of metals could be available for plant uptake. However, the second factor (F2) was strongly associated with the EDTA extractable amount of Mn, $\mathrm{Cr}, \mathrm{Ni}$, and organic matter contents. Such association is more likely to indicate that the extractable amounts of the aforementioned metals are governed by organic matter contents which play a significant role for metal binding. Shuman et al., [35] highlighted that, high amount of organic matter increases both the surface area and binding sites for metal absorption. As a consequence, high concentrations of metals would be available as bioavailable fraction. The third factor (F3) is mostly connecting the bioavailable fraction of $\mathrm{Cu}, \mathrm{Zn}$ with the soil $\mathrm{pH}$ and organic matter contents, indicating that these two parameters are more likely driving the extractable amounts of both $\mathrm{Cu}$ and $\mathrm{Zn}$. Bioavailable fractions of metals such as $\mathrm{Pb}, \mathrm{Zn}$, and $\mathrm{V}$ are correlated

Table 4. Correlation coefficient between EDTA metal extraction and their total concentrations in collected soil, floodplain, and stream sediment samples in Ecton mining area.

\begin{tabular}{|c|c|c|c|c|c|c|c|}
\hline All sample types & $\mathrm{Cu}$ & $\mathbf{P b}$ & Zn & Mn & $\mathrm{Cr}$ & Ni & $\mathbf{V}$ \\
\hline Soil samples $(\mathrm{N}=37)$ & $0.763 * *$ & $0.946^{* *}$ & $0.917 * *$ & $0.840^{* *}$ & 0.035 & $0.408 *$ & 0.097 \\
\hline Floodplain samples $(\mathrm{N}=11)$ & $0.823 * *$ & 0.549 & $0.99 * *$ & $0.862 * *$ & -0.141 & -0.168 & 0.289 \\
\hline Stream sediment samples $(\mathrm{N}=3)$ & $1.00 * *$ & $0.998^{*}$ & 0.964 & -0.985 & $-0.999 *$ & -0.849 & 0.473 \\
\hline
\end{tabular}

**: correlation is significant at 0.01 levels $(2$ tailed $)$

*: correlation is significant at 0.05 levels ( 2 tailed) 
Alibrahim ZO (2016) Assessment of bioavailability of some potential toxic metals in mining-affected soils using EDTA extraction and principle component analysis (PCA) approach, Derbyshire, UK

Table 5. Principal component analysis and factor loading for collected soil samples.

\begin{tabular}{|l|c|c|c|c|}
\hline \multicolumn{5}{|c|}{ Rotated Component Matrix } \\
\hline & \multicolumn{4}{|c|}{ Components $^{\mathbf{2}}$} \\
\cline { 2 - 5 } & $\mathbf{1}$ & $\mathbf{2}$ & $\mathbf{3}$ & $\mathbf{4}$ \\
\hline Cu_bio & -.220 & -.121 & .795 & .001 \\
\hline Pb_bio & -.024 & -.210 & .099 & .865 \\
\hline Zn_bio & .053 & -.275 & .753 & .362 \\
\hline Mn_bio & -.094 & .933 & -.164 & -.039 \\
\hline Cr_bio & -.061 & .934 & -.101 & .141 \\
\hline Ni_bio & .151 & .601 & -.021 & -.248 \\
\hline V_bio & .061 & .067 & .153 & .876 \\
\hline pH_value & .142 & -.089 & .550 & -.010 \\
\hline Organic_M\% & -.058 & .220 & .521 & .342 \\
\hline clay & .895 & -.105 & -.046 & -.029 \\
\hline silt & .858 & .057 & -.113 & -.044 \\
\hline sand & -.846 & -.043 & -.154 & -.098 \\
\hline Eigen Values & 2.955 & 2.382 & 1.950 & 1.137 \\
\hline \% of Variance & 24.623 & 19.854 & 16.250 & 9.476 \\
\hline Cumulative \% & 24.623 & 44.477 & 60.726 & 70.202 \\
\hline
\end{tabular}

Extraction Method: Principal Component Analysis.

Rotation Method: Varimax with Kaiser Normalization.

a. Rotation converged in 5 iterations.

Table 6. Principal component analysis and factor loading for collected floodplain samples.

\begin{tabular}{|l|c|c|c|}
\hline \multirow{2}{*}{} & \multicolumn{3}{|c|}{ Rotated Component Matrix } \\
\hline & $\mathbf{1}$ & Components \\
\hline Cu_bio & .913 & $\mathbf{2}$ & $\mathbf{3}$ \\
\hline Pb_bio & .900 & .139 & .329 \\
\hline Zn_bio & .935 & .141 & .287 \\
\hline Mn_bio & .331 & .171 & .245 \\
\hline Cr_bio & .488 & .530 & .760 \\
\hline Ni_bio & .294 & -.015 & .658 \\
\hline V_bio & .915 & .269 & .932 \\
\hline pH_value & .914 & .079 & .279 \\
\hline Organic_M\% & .698 & .412 & .064 \\
\hline clay & .157 & .932 & .465 \\
\hline silt & .251 & .935 & .166 \\
\hline sand & -.062 & -.923 & .132 \\
\hline Eigen Values & 7.857 & 2.269 & -.069 \\
\hline \% of Variance & 65.478 & 18.906 & 1.049 \\
\hline Cumulative \% & 65.478 & 84.385 & 8.739 \\
\hline
\end{tabular}

Extraction Method: Principal Component Analysis.

Rotation Method: Varimax with Kaiser Normalization.

a. Rotation converged in 5 iterations.

with the organic matter contents in the fourth Factor (F4), with approximately similar factor loading for $\mathrm{Pb}$ and $\mathrm{V}$. such association, similar to the case of F4, may seem to indicate that organic matter contents control the bioavailable portion of these elements.

However, regarding the floodplain soils, three principal factors were extracted (Table 5), which illustrate $93 \%$ of the total variance (Table 6). The strongest association of the data is explained by the first factor (F1) with mostly correlated with bioavailable fraction of $\mathrm{Cu}, \mathrm{Pb}$, $\mathrm{Zn}, \mathrm{V}$, organic matter contents and soil $\mathrm{pH}$, whilst clay and silt fractions display a weaker correlation. Similar to the third factor of soil samples, both organic matter contents and $\mathrm{pH}$ values are likely to be very important factors in terms of the bioavailable amount of $\mathrm{Cu}, \mathrm{Pb}, \mathrm{Zn}$, and $\mathrm{V}$. on the other hand, a strong correlation was found by the second factor (F2) which connecting the bioavailability of $\mathrm{Mn}$, and $\mathrm{V}$ with clay
Table 7. Principal component analysis and factor loading for collected stream sediment samples.

\begin{tabular}{|l|c|c|}
\hline \multicolumn{3}{|c|}{ Rotated Component Matrix $^{\mathbf{a}}$} \\
\hline & $\mathbf{1}$ & Components $^{*}$ \\
\hline Cu_bio & -.193 & $\mathbf{2}$ \\
\hline Pb_bio & -.353 & .981 \\
\hline Zn_bio & -.173 & .935 \\
\hline Mn_bio & .972 & .985 \\
\hline Cr_bio & .881 & -.236 \\
\hline Ni_bio & .320 & -.474 \\
\hline V_bio & .851 & .948 \\
\hline pH_value & .900 & .526 \\
\hline Organic_M\% & -.063 & .435 \\
\hline clay & 1.000 & .998 \\
\hline silt & .930 & .022 \\
\hline sand & -.954 & -.368 \\
\hline Eigen Values & 6.923 & .298 \\
\hline \% of Variance & 57.690 & 5.077 \\
\hline Cumulative \% & 57.690 & 42.310 \\
\hline
\end{tabular}

Extraction Method: Principal Component Analysis.

Rotation Method: Varimax with Kaiser Normalization.

a. Rotation converged in 5 iterations.

fraction, silt fraction, and organic matter contents. Such association is likely attributed to the fact that these factors might provide bigger surface area for absorption, thereby high concentrations of these metals area expected, resulting high bioavailability. The bioavailable fraction of all studied metals shows a positive relationship with organic matter contents in the component 3 (F3), with a stronger association of $\mathrm{Mn}$ and Ni. Likewise, the case of the third factor (F3) in soil samples, such relationship might seem to indicate that the contents of organic are governing the bioavailable fractions of the studied metals. In the case of stream sediment samples, two principle components were extracted which describe the whole variance (Table 5). it could be seen that, the bioavailable fractions of $\mathrm{Mn}, \mathrm{Cr}, \mathrm{Ni}, \mathrm{V}$, soil $\mathrm{pH}$, clay and silt fractions show a strong positive correlation with the first component (F1) (Table 6), while organic matter contents show a negative association. Such association was also found in the case of the first factor (F1) for the soil samples, and may indicate that clay and silt particles are most likely controlling the extraction amounts of the aforementioned metals due to the fact that, as has been mentioned before, these two factors present high surface area for metal absorption, and hence elevated concentrations would be available for plant uptake. However, the bioavailable fraction of $\mathrm{Cu}, \mathrm{Pb}, \mathrm{Zn}, \mathrm{Ni}, \mathrm{V}$, soil $\mathrm{pH}$, and organic matter contents correlate strongly and positively with the second factor (F2). Such correlation, as has been previously discussed, is most likely attributed to the large surface area that fine grain fractions and organic matter contents could provide for metal absorption, providing high amounts of these metals to be available for plant roots.

It could be concluded that, PCA analysis has shown different association forms between the bioavailable fractions of studied heavy metals and soil specific parameters (i.e., $\mathrm{pH}$, organic matter amounts, and different particle size range. However, the effect of these parameters is various among different soil types, with predominant influence of the clay and silt fraction especially in the case of stream sediment samples in which clay and silt size range show a strong association with the bioavailable amounts of extracted metals (Table 7) [36-38].

\section{Conclusions}

In the present study, the bioavailability of some selected heavy 
Alibrahim ZO (2016) Assessment of bioavailability of some potential toxic metals in mining-affected soils using EDTA extraction and principle component analysis (PCA) approach, Derbyshire, UK

metals (i.e., $\mathrm{Cu}, \mathrm{Pb}, \mathrm{Zn}, \mathrm{Mn}, \mathrm{Cr}, \mathrm{Ni}$, and $\mathrm{V}$ ) in topsoils, floodplain soils, and stream sediment samples, has been examined using one batch EDTA extraction approach. Results revealed that the bioavailable fraction of $\mathrm{Cu}, \mathrm{Pb}, \mathrm{Zn}$, and $\mathrm{Mn}$ was the highest in the three types of soil, whereas, the lowest value was found for $\mathrm{Cr}, \mathrm{Ni}$, and V. similarly, on the basis of the calculated bioavailable ratios, these metals were also found to have the uppermost values, suggesting an anthropogenic source (i.e., former mining operations in the area) for such levels. In addition, comparing with the national average amounts in England and Wales, the EDTA- $\mathrm{Cu}, \mathrm{Pb}$, and $\mathrm{Zn}$ contents were 3.53, 7.47, and 10.72 , respectively, times the national average amounts.

Person correlation coefficients between the EDTA extractable contents of the studied metals and their total concentrations have revealed a positive and strong association especially in the case of topsoils with a significant level of (0.01) for $\mathrm{Cu}, \mathrm{Pb}, \mathrm{Zn}$, and $\mathrm{Mn}$. Furthermore, the principle component analysis (PCA) data indicated that organic matter contents and the granulometric fractions of clay and silt are the key control on the bioavailability of examined heavy metals.

\section{Acknowledgments}

The authors are thankful for the financial support from the Iraqi Government- Ministry of Higher Education and Scientific Research. Also, we would like to extend our grateful to Miss Diane Spencer for her help with ICP-OE S analysis, and Mr David Townrow for his valuable comments at the University of Wolverhampton- Faculty of Science and Engineering.

\section{References}

1. Davies BE (1983) Heavy Metal Contamination from Base Metal Mining and Smelting: Implications from Man and His Environment. In. Thornton, Applied Environmental Geochemistry: 425- 462.

2. Adriano D, Wenzel W, Vangronsveld J, Bolans NS (2004) Role of assisted natural remediation in environmental clean-up. Geoderma 122: 121-142.

3. Maff, Mistry of Agriculture, Fisheries and Food (1986) Reference Book 427. The analysis of agriculture materials. HMSO, London.

4. Gleyzes C, Tellier S, Astruc M, (2002) Fractionation studies of trace elements in contaminated soils and sediments: a review of sequential extraction procedures. $\operatorname{Tr} A C$ Trends in Analytical Chemistry 21: 451-467.

5. Mcgrath S, Loveland P (1992) The soil geochemical atlas of England and Wales. Blackie Academic \& Professional.

6. Hamon R, Wundke J, Mclaughlin M, Naidu R (1997) Availability of zinc and cadmium to different plant species. Australian Journal of Soil Research 35: 1267-1277.

7. Alloway BJ (1995) Soil process and the behaviour of heavy metals in: Alloway, B. J. (ed): Heavy Metals in Soils, Blackie Academic \& Professional, 3-57

8. Grinsted M, Hedley M, White R, Nye P (1982) Plant-induced changes in the rhizosphere of rape (Brassica napus var. Emerald) seedlings. New Phytologist 91: 19-29.

9. Reijonen I, Metzler M, Hartikainen H (2016) Impact of soil pH and organic matter on the chemical bioavailability of vanadium species: The underlying basis for risk assessment. Environ Pollut 210: 371-379. [Crossref]

10. Mench M, Martin E (1991) Mobilization of cadmium and other metals from two soils by root exudates of Zea mays L., Nicotiana tabacum L. and Nicotiana rustica L. Plant and Soil 132: 187-196.

11. ICRCL, Interdepartmental Committee on the Redevelopment of Contaminated Land (1990) Notes on the restoration and aftercare of metalliferous mining sites for pasture and grazing, 1St edn. Department of Environment, ICRCL Guidance Note 70/90, London. 1990.

12. Geeson N, Abrahams P, Murphy M, Thornton I (1998) Fluorine and metal enrichment of soils and pasture herbage in the old mining areas of Derbyshire, UK. Agriculture, Ecosystems \& Environment 68: 217-231.

13. Harris H (1971) The industrial archaeology of the Peak District. David \& Charles Publishers.
14. Cope FW (1973) Woo Dale Borehole near Buxton, Derbyshire. Nature 243: 29-30.

15. Dunham K (1973) A recent deep borehole near Eyam, Derbyshire. Nature 241: 84-85.

16. Young EA (2006) Monitoring and measuring the impacts and environmental implications of flood events on contaminated sediment dispersal in the River Swale catchment, North Yorkshire,

17. Macklin MG, Dowsett RB (1989) The chemical and physical speciation of trace metals in fine grained overbank flood sediments in the Tyne basin, north-east England. Catena 16: $135-151$.

18. Tessier A, Campbell PG, Bisson M (1979) Sequential extraction procedure for the speciation of particulate trace metals. Analytical Chemistry 51: 844-851.

19. Taylor MP (1996) The variability of heavy metals in floodplain sediments: a case study from mid Wales. Catena 28: 71-87.

20. Quevauviller P (1998) Method performance studies for speciation analysis. Royal Society of Chemistry.

21. Kashem M, Singh B (2001) Metal availability in contaminated soils: II. Uptake of Cd, $\mathrm{Ni}$ and $\mathrm{Zn}$ in rice plants grown under flooded culture with organic matter addition. Nutrient Cycling in Agroecosystems 61: 257-266.

22. Sanchez J, Marino N, Vaquero M, Ansorena J, Legorburu I (1998) Metal pollution by old lead-zinc mines in Urumea River valley (Basque Country, Spain). Soil, biota and sediment. Water, air, and soil pollution 107: 303-319.

23. Bradley S, Cox J (1986) Heavy metals in the Hamps and Manifold valleys, North Staffordshire, UK: distribution in floodplain soils. Science of the Total Environment 50: 103-128.

24. Abrahams PW, Steigmajer J (2003) Soil ingestion by sheep grazing the metal enriched floodplain soils of mid-Wales. Environ Geochem Health 25: 17-24. [Crossref]

25. Läcätuýu R, Räutä C, Cärstea S, Ghelase I (1996) Soil-plant-man relationships in heavy metal polluted areas in Romania. Applied Geochemistry 11: 105-107

26. Bunzl K, Trautmannsheimer M, Schramel P, Reifenhäuser W (2001) Availability of arsenic, copper, lead, thallium, and zinc to various vegetables grown in slagcontaminated soils. J Environ Qual 30: 934-939. [Crossref]

27. Albering HJ, van Leusen SM, Moonen EJ, Hoogewerff JA, Kleinjans JC (1999) Human health risk assessment: A case study involving heavy metal soil contamination after the flooding of the river Meuse during the winter of 1993-1994. Environ Health Perspect 107: 37-43. [Crossref]

28. Archer F, Hodgson I (1987) Total and extractable trace element contents of soils in England and Wales. Journal of Soil Science 38: 421-431.

29. Li X, Thornton I (2001) Chemical partitioning of trace and major elements in soils contaminated by mining and smelting activities. Applied Geochemistry 16: 1693-1706.

30. Morton-bermea O, Hernandez E, Martinez-pichardo E, Soler-arechalde A, Santa-cruz, et al. (2009) Mexico City topsoils: Heavy metals vs. magnetic susceptibility. Geoderma 151: $121-125$.

31. Cheshire M, Berrow M, Goodman B, Mundie C (1977) Metal distribution and nature of some $\mathrm{Cu}, \mathrm{Mn}$ and $\mathrm{V}$ complexes in humic and fulvic acid fractions of soil organic matter. Geochimica et Cosmochimica Acta 41:1131-1138.

32. Yaru BT, Buckney RT (2000) Predicting the availability of copper to rooted, emergent aquatic macrophytes from the Fly River floodplain, Papua New Guinea. International Journal of Ecology and Environmental Sciences 26: 49-65.

33. Einax JW, Zwanziger HW, Geiss S (1997) Chemometrics in environmental analysis. John Wiley \& Sons.

34. Brady NC (1984) The Nature and Properties of Soils. 9th edn edn. Collier Macmillan.

35. Shuman L, Dudka S, Das K (2002) Cadmium forms and plant availability in compostamended soil. Communications in Soil Science and Plant Analysis 33: 737-748.

36. John barnatt (2013) Delving Ever Deeper: The Ecton Mines through time illustrated edn. Peak District National Park Authority.

\section{ORDINANCE SURVEY, EDINA \& NERC, (2009) Digimap.}

38. Weber J, Karczewska A (2004) Biogeochemical processes and the role of heavy metals in the soil environment. Geoderma 122: 105-107.

Copyright: (C2016 Alibrahim ZO. This is an open-access article distributed under the terms of the Creative Commons Attribution License, which permits unrestricted use, distribution, and reproduction in any medium, provided the original author and source are credited. 